\title{
Comparison of Geophysical Model Functions for SAR Wind Speed Retrieval in Japanese Coastal Waters
}

\author{
Yuko Takeyama $^{1, *}$, Teruo Ohsawa ${ }^{2}$, Katsutoshi Kozai ${ }^{2}$, Charlotte Bay Hasager ${ }^{3}$ \\ and Merete Badger ${ }^{3}$
}

1 National Institute of Advanced Industrial Science and Technology, 1-1-1 Umezono, Tsukuba, Ibaraki 305-8568, Japan

2 Graduate School of Maritime Science, Kobe University, 5-1-1 Fukaeminamimachi, Higashinadaku, Kobe, Hyogo 658-0022, Japan; E-Mails: ohsawa@ @ort.kobe-u.ac.jp (T.O.); kouzai@maritime.kobe-u.ac.jp (K.K.)

3 Department of Wind Energy, Technical University of Denmark, Frederiksborgvej 399, 4000 Roskilde, Denmark; E-Mails: cbha@dtu.dk (C.H.); mebc@dtu.dk (M.B.)

* Author to whom correspondence should be addressed; E-Mail: takeyama.yuko@aist.go.jp; Tel.: +81-29-862-6723; Fax: +81-29-862-6601.

Received: 13 February 2013; in revised form: 18 March 2013 / Accepted: 16 April 2013 / Published: 19 April 2013

\begin{abstract}
This work discusses the accuracies of geophysical model functions (GMFs) for retrieval of sea surface wind speed from satellite-borne Synthetic Aperture Radar (SAR) images in Japanese coastal waters characterized by short fetches and variable atmospheric stability conditions. In situ observations from two validation sites, Hiratsuka and Shirahama, are used for comparison of the retrieved sea surface wind speeds using CMOD (C-band model)4, CMOD_IFR2, CMOD5 and CMOD5.N. Of all the geophysical model functions (GMFs), the latest C-band GMF, CMOD5.N, has the smallest bias and root mean square error at both sites. All of the GMFs exhibit a negative bias in the retrieved wind speed. In order to understand the reason for this bias, all SAR-retrieved wind speeds are separated into two categories: onshore wind (blowing from sea to land) and offshore wind (blowing from land to sea). Only offshore winds were found to exhibit the large negative bias, and short fetches from the coastline may be a possible reason for this. Moreover, it is clarified that in both the unstable and stable conditions, CMOD5.N has atmospheric stability effectiveness, and can keep the same accuracy with CMOD5 in the neutral condition. In short, at the moment, CMOD5.N is thought to be the most promising GMF for the SAR wind speed retrieval with the atmospheric stability correction in Japanese
\end{abstract}


coastal waters, although there is ample room for future improvement for the effect from short fetch.

Keywords: satellite-borne SAR; geophysical model function; sea surface wind speed retrieval

\section{Introduction}

Estimation of sea surface wind speed has been attempted since the 1980s using a microwave scatterometer and a geophysical model function (GMF), which describes the relationship between microwave backscatter, local incidence angle, relative wind direction and wind speed at $10 \mathrm{~m}$ height above the mean sea level (MSL). Nowadays, wind field maps using the GMF are practically utilized [1].

Multiple GMFs with the common name CMOD (C-band model) have been developed. An early C-band GMF, CMOD2, was formulated as a prelaunch model for the ERS (European Remote Sensing Satellite)-1 based on airborne scatterometer data. CMOD4 [2] was developed based on both the ERS-1 scatterometer and Synthetic Aperture Radar (SAR) data. Although CMOD4 has been frequently validated in previous studies [3-5], Stoffelen [6] suggested that CMOD4-retrieved wind speeds are negatively biased by $4 \%$. In addition, CMOD4 cannot retrieve high wind speeds ( $24 \mathrm{~m} / \mathrm{s}$ and above). Meanwhile, CMOD_IFR2 [7] was developed independently from CMOD4. CMOD_IFR2 was also calibrated for the ERS-1 scatterometer based on buoy and analysis data. CMOD5 was developed to overcome the weak points of CMOD4, and has been used recently [8], but it still has negative biases [9]. In order to eliminate this negative bias, the latest GMF, CMOD5.N [9,10], was developed by refitting 28 coefficients of CMOD5 to reduce the negative bias, and CMOD5.N retrieves $0.5 \mathrm{~m} / \mathrm{s}$ higher wind speed than CMOD5 on average for the correction.

A distinguishing feature of CMOD5.N is that it can retrieve the equivalent neutral wind speed (ENW) [11], whereas CMOD4 and CMOD5 retrieve a non-neutral wind speed, which is referred to in this study as the stability-dependent wind speed (SDW) meaning a real wind speed. A scatterometer and SAR do not directly measure the $10 \mathrm{~m}$-height wind speed, but they observe backscatter from the sea surface. The intensity of the backscatter depends on the sea surface roughness or frictional velocity, which can be related to the $10 \mathrm{~m}$-height wind speed through the Monin-Obukhov similarity theory [12]. That is, in the surface layer, wind speed increases with height, and the deviation from the logarithmic profile is determined by atmospheric stability. Thus, ideally, the $10 \mathrm{~m}$-height wind speed should be retrieved taking atmospheric stability into account, and this is possible using CMOD5.N. The CMOD5.N-retrieved ENW can be converted to a SDW taking the atmospheric stability into account by using external input data of sea surface temperature, air temperature and relative humidity. As an offset for atmospheric stability, a value of $0.2 \mathrm{~m} / \mathrm{s}$ is added in CMOD5.N compared to CMOD5 [9] on average. Along with the $0.5 \mathrm{~m} / \mathrm{s}$ enhancement applied to eliminate the negative bias mentioned above, the difference between the wind speeds retrieved by CMOD5.N and CMOD5 is $0.7 \mathrm{~m} / \mathrm{s}$ on average. Meanwhile, CMOD_IFR2 also was adjusted to near neutral wind speeds [7].

The purpose of this study is to identify the most promising GMF for the SAR wind speed retrieval in Japanese coastal waters, which are greatly affected by complex coastal topography and variable atmospheric stability due to prevailing monsoon winds and warm and cold ocean currents. Four 
C-band GMFs; CMOD4, CMOD_IFR2, CMOD5 and CMOD5.N, are compared with each other using 106 ENVISAT (ENVIronmental SATellite) Advanced SAR images at two validation sites, Hiratsuka and Shirahama, in Japanese coastal waters. The methods are described in Section 2. General results are shown in Section 3.1, and discussions on effect of fetch, and the effectiveness of the correction for atmospheric stability with CMOD5.N are described in Sections 3.2 and 3.3, respectively. Finally, conclusions are given in Section 4.

\section{Methods}

\subsection{In situ Measurements and Synthetic Aperture Radar (SAR) Images}

The two target coastal waters of this study are Hiratsuka and Shirahama in Japan, where there are offshore platforms conducting meteorological observations. The geographical locations of the Hiratsuka offshore platform $\left(35^{\circ} 18^{\prime} 20^{\prime \prime} \mathrm{N}, 139^{\circ} 20^{\prime} 45^{\prime \prime} \mathrm{E}\right)$ operated by the Institute of Industrial Science (IIS) of the University of Tokyo, and the Shirahama offshore platform (33 $\left.42^{\prime} 32^{\prime \prime} \mathrm{N}, 135^{\circ} 19^{\prime} 58^{\prime \prime} \mathrm{E}\right)$ operated by the Disaster Prevention Research Institute (DPRI) of Kyoto University are shown in Figure 1. These platforms have distances of $1 \mathrm{~km}$ and $2 \mathrm{~km}$ from coast lines, respectively. On the two platforms, 10-min-average wind speed and direction are measured at a height of $23 \mathrm{~m}$ above the MSL by a propeller anemometer. These measured wind speeds are used to validate the sea surface wind speeds retrieved from SAR images.

Figure 1. Geographical locations of the Hiratsuka (a) and Shirahama (b) offshore platforms (indicated by black circles in the inserts).

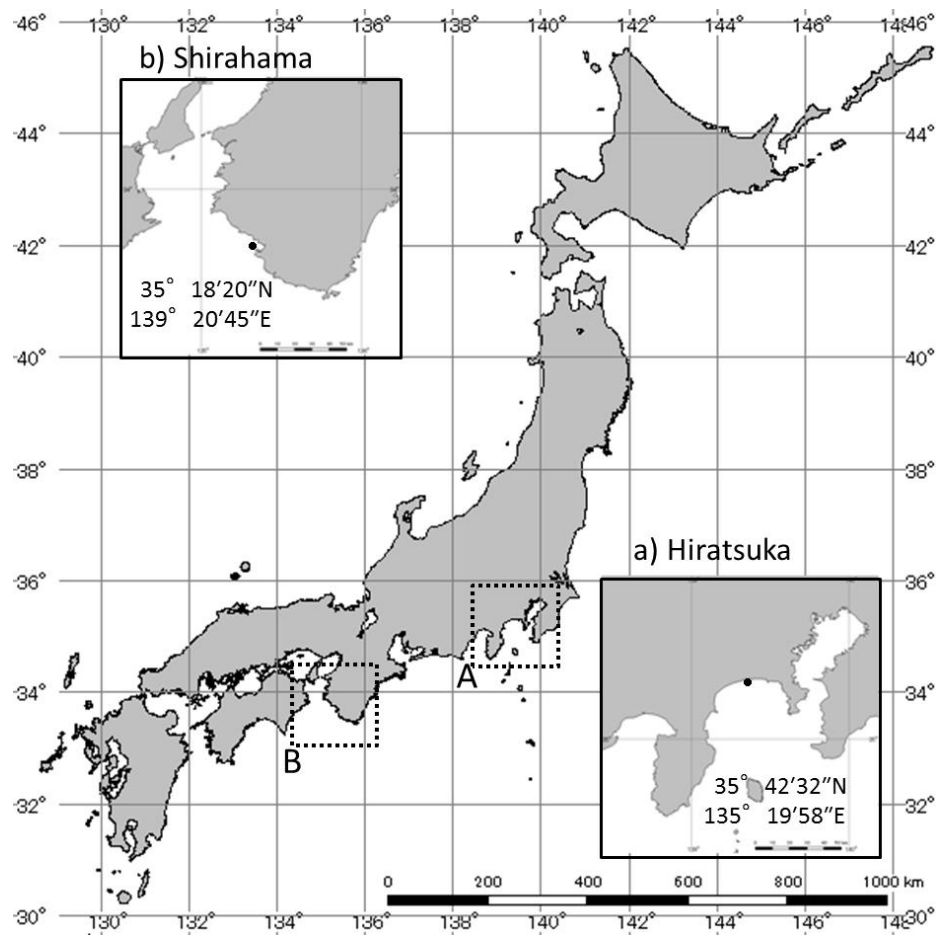

This study uses images from the C-band Advanced SAR onboard the ENVISAT satellite, launched by the European Space Agency in 2002. In total, 106 Advanced SAR images with HH polarization for a horizontal transmit and a horizontal receive, and VV polarization for a vertical transmit and a vertical 
receive (Hiratsuka: 33 images, and Shirahama: 73 images) recorded with $12.5 \mathrm{~m}$ pixel spacing for the Precision Image Product (IMP) and $75.0 \mathrm{~m}$ pixel spacing for Wide Swath Mode (WSM) are used to retrieve sea surface wind speeds. All 106 images are listed in Appendixes 1 (Hiratsuka) and 2 (Shirahama). The SAR images are smoothed to $400 \mathrm{~m}$ spatial resolution using the Cressman method [13] to remove speckle noise. Though it is expected that these platforms themselves make errors in SAR images, these errors also can be eliminated by the smoothing as well as the speckle noise as previous study reported [14].

\subsection{C-Band Geophysical Model Function (GMF)}

Winds retrieved from four C-band GMFs, CMOD4, CMOD5, CMOD_IFR2, and CMOD5.N are compared with in situ measurements at Hiratsuka and Shirahama. The lower limit of wind speed retrieved from a GMF is known to be 1 to $3 \mathrm{~m} / \mathrm{s}$ [15-17]. Thus, this paper excludes in situ wind speeds of less than $2 \mathrm{~m} / \mathrm{s}$ at $23 \mathrm{~m}$ height from the validation. For CMOD4, the primary equation is written as

$$
\sigma_{v v}^{0}=b_{0}\left(1.0+b_{1} \cos \phi+b_{3} \tanh \left(b_{2}\right) \cos (2 \phi)\right)^{1.6},
$$

for CMOD_IFR2, it is

$$
\sigma_{v v}^{0}=10.0^{\alpha+\beta \sqrt{v}}\left(1.0+b_{1} \cos \phi+\tanh b_{2} \cos 2 \phi\right)
$$

and for CMOD5 and CMOD5.N, it is

$$
\sigma_{v v}^{o}=b_{0}\left(1.0+b_{1} \cos \phi+b_{2} \cos (2 \phi)\right)^{1.6}
$$

where $\sigma_{v v}^{0}$ is the VV-polarized Normalized Radar Cross Section (NRCS) and $\varphi$ is the relative direction between the radar look direction and the wind direction. The other parameters, $b_{i}(i=0,1,2,3)$ depend on the radar incidence angle and wind speed. The relative wind direction should be acquired from other external sources, whereas the NRCS and the incidence angle can be obtained from an SAR image. In situ wind directions are used as input to the GMFs in this study, although some methods to acquire wind directions from an SAR image itself or numerical simulations have been proposed (e.g., [18-20]).

Since all the C-band GMFs have been developed for VV-polarized NRCS $\left(\sigma_{v v}^{0}\right)$, HH-polarized NRCS ( $\sigma_{h h}^{0}$ ) must be corrected by an empirical equation before the GMF processing. In order to convert from $\sigma_{h h}^{0}$ to $\sigma_{v v}^{0}$, the equation [21]:

$$
\frac{\sigma_{v v}^{0}}{\sigma_{h h}^{0}}=C_{0}(\theta)+C_{1}(\theta)+\cos \phi+C_{2}(\theta) \cos 2 \phi
$$

is applied. $C i(i=0,1,2)$ are the ratios between $\mathrm{HH}$ and $\mathrm{VV}$-polarized NRCSs for three wind directions, upwind, downwind and crosswind, respectively.

\subsection{Height Correction of In situ Wind Speed}

A GMF can retrieve the sea surface wind speed at a $10 \mathrm{~m}$ height above the MSL, whereas the in situ wind speed is measured at $23 \mathrm{~m}$ above MSL at both offshore platforms. Thus, height correction of the in situ wind speed is necessary to enable direct comparison with the retrieved wind speeds from the SAR images. For this height correction, the LKB code [22] is used to estimate the $10 \mathrm{~m}$-height wind speed from 23 m-height wind speed. The LKB code requires three kinds of input data, air 
temperature, relative humidity, and sea surface temperature (SST) for the estimation. This study principally uses values from in situ measurements. But, since air temperature is not measured at Hiratsuka, those simulated with the meteorological mesoscale model WRF (the Weather Research and Forecasting model [23]) are used instead of in situ measurements. For this simulation, the Advanced Research WRF model version 3.0 is used, and the model configuration is shown in Appendix. In the LKB code, the following wind profile based on the Monin-Obukhov similarity theory is used, taking the effect of atmospheric stability, expressed as $\Psi u(z / L)$, into account.

$$
u=\frac{u_{*}}{\kappa}\left[\ln \left(\frac{Z}{z_{0}}\right)-\Psi_{u}\left(\frac{Z}{L}\right)\right]
$$

Here, $u *$ is frictional velocity, $z_{0}$ is roughness length, $z$ is height, $L$ is Monin-Obukhov length, and $\kappa$ is the von Karman constant $(=0.4)$. The relation between $z_{0}$ and $u *$ is given as

$$
z_{0}=0.11 \frac{v}{u_{*}}+z_{c h} \frac{u_{*}^{2}}{g}
$$

where $z_{c h}$ is Charnock's parameter with a value of 0.011 [24], $v$ is the kinematic viscosity, and $g$ is the acceleration due to gravity. The parameters of $z_{0}$ and $u *$ can be determined iteratively.

\subsection{Conversion from $E N W$ to $S D W$}

ENW represents the wind at $10 \mathrm{~m}$ height for given surface stress in case the marine boundary layer is neutrally stratified, while SDW means real wind speed. In order to compare CMOD_IFR2- and CMOD5.N-retrieved ENW with in situ wind speeds in the validation, the ENW is converted to SDW, which is comparable to the in situ wind speed. Hereinafter, the SDW obtained from CMOD_IFR2 and CMOD5.N with the LKB code is referred to as CMOD_IFR2_SDW and CMOD5.N_SDW, while the ENW originally obtained from CMOD_IFR2 and CMOD5.N is referred to as CMOD_IFR2_ENW and CMOD5.N_ENW. The logarithmic wind profile,

$$
u_{E N W}=\frac{u_{*}}{\kappa} \ln \left(\frac{Z}{z_{0}}\right)
$$

is first used for the calculation of frictional velocity $u *$ from the ENW. Then the SDW is calculated using Equation (5). The flowchart of the wind retrieval from an Advanced SAR image and its validation with an in situ wind speed is depicted in Figure 2.

Figure 2. Flowchart of wind retrieval from an Advanced SAR image and validation with in situ wind speed.

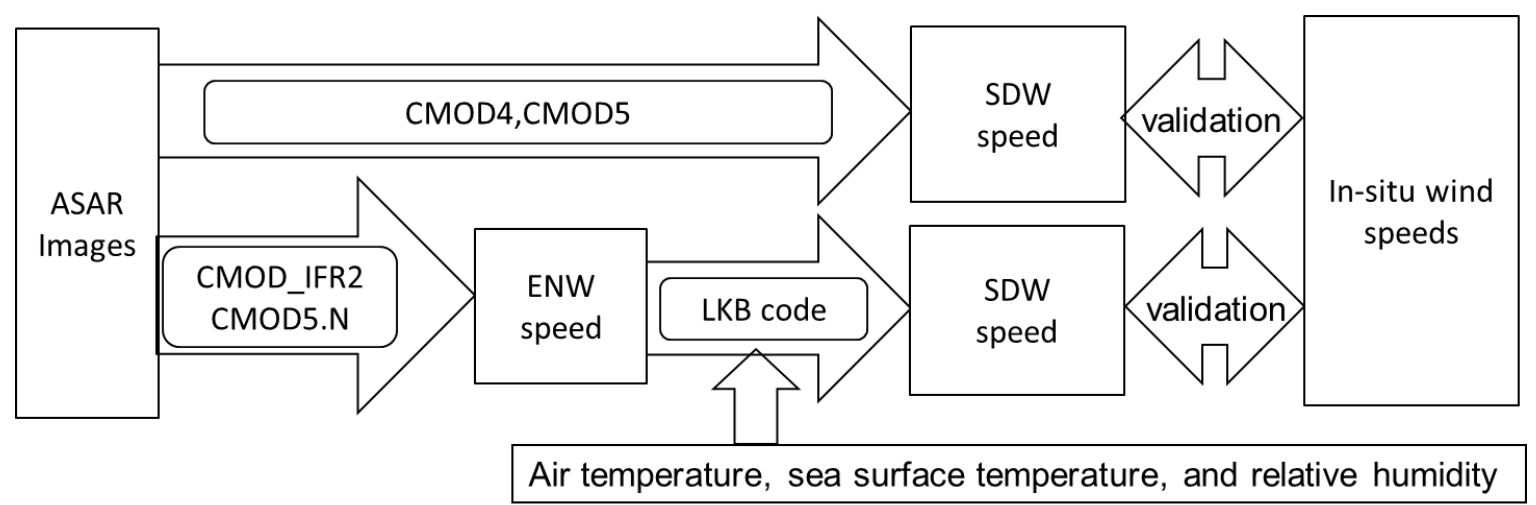




\section{Results and Discussion}

\subsection{Accuracies of Wind Speed Retrieval Using Four GMFs}

Accuracies of the wind speed retrieved by four GMFs: CMOD4, CMOD_IFR2, CMOD5, and CMOD5.N, are compared at the two validation sites, Hiratsuka and Shirahama. Figure 3 shows relations between in situ wind speeds and retrieved wind speeds from 33 SAR images using the four GMFs at Hiratsuka. The root mean square errors (RMSEs) of these SAR-retrieved wind speeds are $2.17 \mathrm{~m} / \mathrm{s}$ (CMOD4), $2.34 \mathrm{~m} / \mathrm{s}$ (CMOD_IFR2_SDW), $2.06 \mathrm{~m} / \mathrm{s}$ (CMOD5) and $2.03 \mathrm{~m} / \mathrm{s}$ (CMOD5.N_SDW), and the biases are $-1.15 \mathrm{~m} / \mathrm{s}$ (CMOD4), $-1.31 \mathrm{~m} / \mathrm{s}$ (CMOD_IFR2_SDW), $-0.98 \mathrm{~m} / \mathrm{s}$ (CMOD5) and $-0.77 \mathrm{~m} / \mathrm{s}$ (CMOD5.N_SDW), respectively. Thus, CMOD5.N_SDW has the smallest RMSE and bias at Hiratsuka. Figure 4 is the same as Figure 3, but for Shirahama, using 73 SAR images. The RMSEs of these SAR-retrieved wind speeds are $1.97 \mathrm{~m} / \mathrm{s}$ (CMOD4), $2.05 \mathrm{~m} / \mathrm{s}$ (CMOD_IFR2_SDW), $1.77 \mathrm{~m} / \mathrm{s}$ (CMOD5) and $1.76 \mathrm{~m} / \mathrm{s}$ (CMOD5.N_SDW), respectively and the biases are $-1.10 \mathrm{~m} / \mathrm{s}$ (CMOD4), $-1.06 \mathrm{~m} / \mathrm{s}$ (CMOD_IFR2_SDW), $-0.64 \mathrm{~m} / \mathrm{s}$ (CMOD5) and $-0.42 \mathrm{~m} / \mathrm{s}$ (CMOD5.N_SDW), respectively. All the statistic values are concluded in Table 1. These results show that CMOD5.N_SDW has the smallest RMSE and bias at Shirahama as well as Hiratsuka. Meanwhile, the retrieved wind speeds from WSM are also shown as squares in Figure 4, and the statistic values are shown in parentheses. No large difference is found in wind speed between WSM and IMP for all the GMFs.

Figure 3. Relations between 33 SAR-retrieved wind speeds and in situ wind speeds at Hiratsuka using four GMFs: (a) CMOD4, (b) CMOD_IFR2, (c) CMOD5, and (d) CMOD5.N.
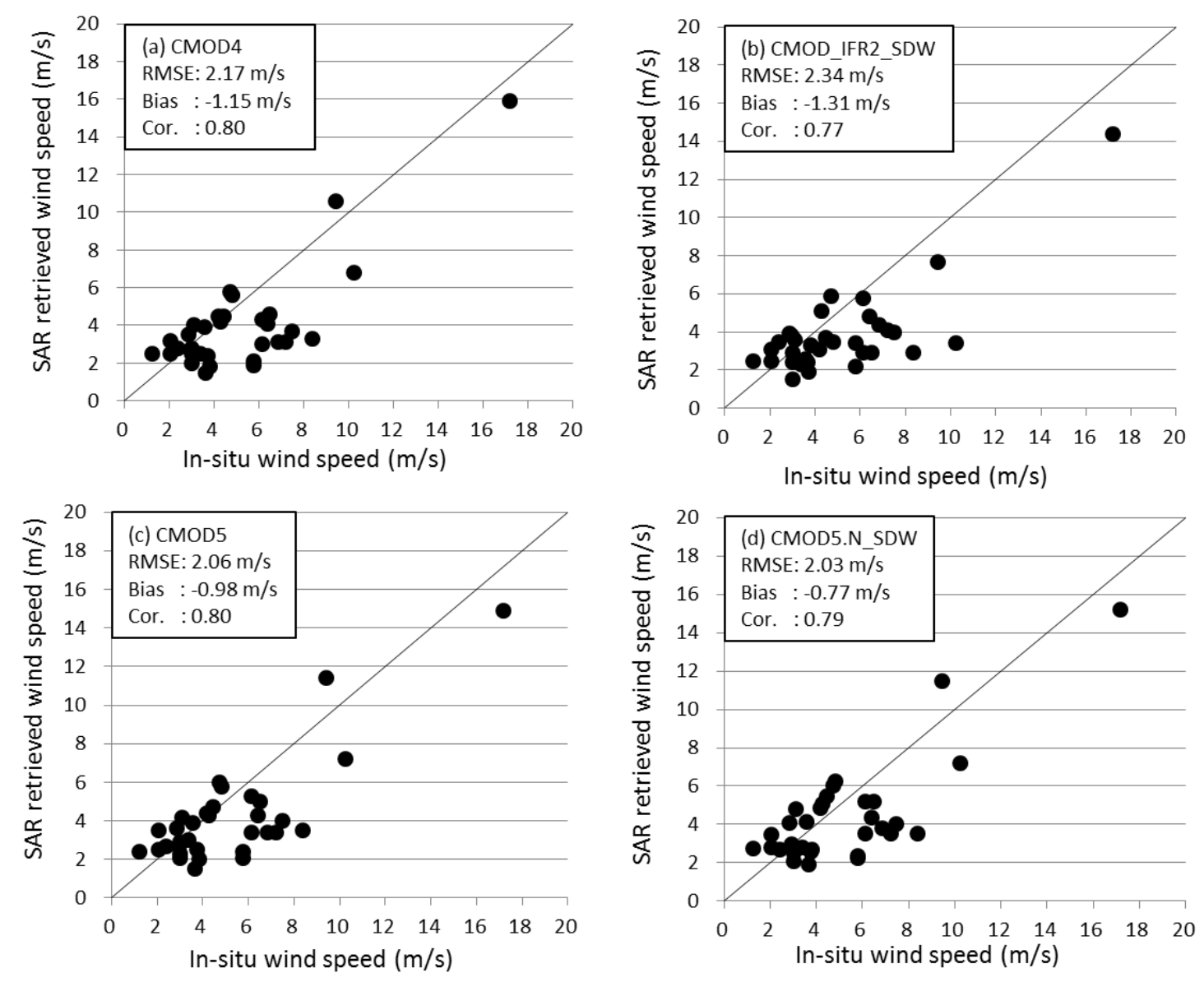
Figure 4. Same as Figure 3, but for 73 cases observed by IMP (daub circle) and WSM (square) at Shirahama. The statistics are for 73 cases, and those for WSM (31 cases) are in parentheses.
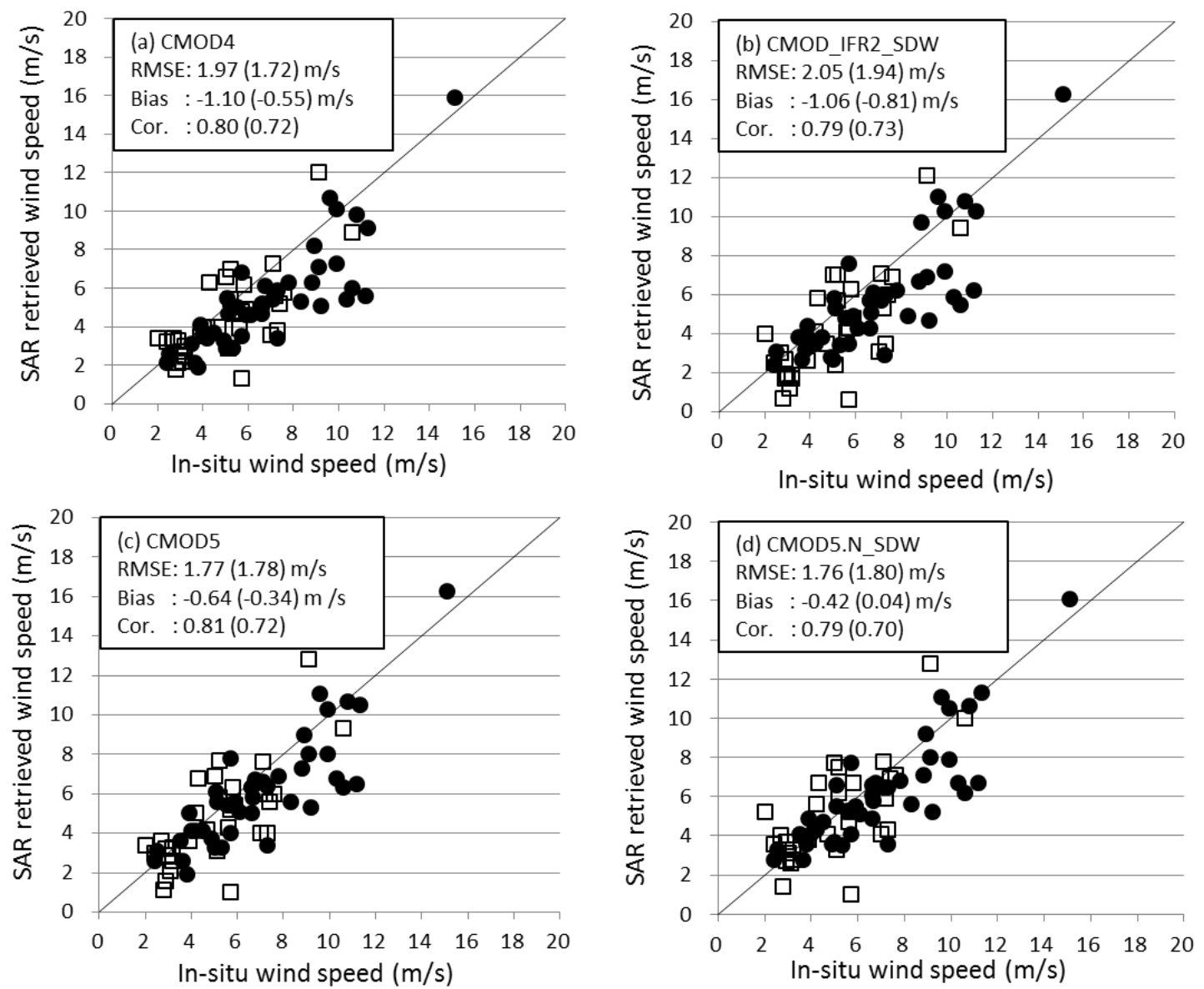

Table 1. RMSEs, biases and correlation coefficients of wind speeds retrieved by four GMFs at both Hiratsuka and Shirahama.

\begin{tabular}{llrrrr}
\hline & & CMOD4 & CMOD_IFR2_SDW & CMOD5 & CMOD5.N_SDW \\
\hline \multirow{4}{*}{ Hiratsuka } & RMSE (m/s) & 2.17 & 2.34 & 2.06 & 2.03 \\
& Bias (m/s) & -1.15 & -1.31 & -0.98 & -0.77 \\
& Correlation coef. & 0.80 & 0.77 & 0.80 & 0.79 \\
& RMSE (m/s) & 1.97 & 2.05 & 1.77 & 1.76 \\
& Bias (m/s) & -1.10 & -1.06 & -0.64 & -0.42 \\
& Correlation coef. & 0.80 & 0.79 & 0.81 & 0.79 \\
\hline
\end{tabular}

All of the GMFs exhibit a negative bias in the retrieved wind speed at both validation sites. The absolute value of the negative bias in CMOD5.N_SDW is the smallest of all the GMFs, followed by CMOD5, CMOD4, and CMOD_IFR2_SDW in ascending order at both validation sites. These negative biases from CMOD4 and CMOD5 were reported in the previous study [10] as well. However, CMOD5.N, which has been developed to eliminate the negative bias, is found to still have a negative bias in this study. Moreover, the negative bias is much larger than that reported in previous studies such as [25,26], which showed that even the negative bias in CMOD5 is around $-0.5 \mathrm{~m} / \mathrm{s}$. These facts indicate that the SAR wind speeds retrieved at Hiratsuka and Shirahama are affected by some factors that cause the larger negative biases. A possible factor for the negative bias is the effect of a short fetch as described in the previous study [10]. This short fetch effect is discussed in detail in Section 3.2. 


\subsection{Effect of Short Fetch on Wind Speed Retrieval}

In addition to wind speed, the fetch and duration of wind blowing over the sea surface can also change the sea surface roughness, especially in coastal waters. Thus, in this study, a short fetch is suspected to affect the sea surface roughness, resulting in the negative bias in the retrieved wind speed. To extract the short fetch effect on the SAR-retrieved wind speed, all the data are separated into two categories: offshore wind (blowing from land to sea) and onshore wind (blowing from sea to land). The onshore wind is defined as wind with a wind direction between 110 to 210 degrees at Hiratsuka, and 205 to 310 degrees at Shirahama, based on a threshold fetch of $30 \mathrm{~km}$. This is because the previous study [27] shows that the wind speed growth with fetch is influenced by upwind terrain within $30 \mathrm{~km}$ from the coastline. Figure 5 shows scatter plots of 22 onshore winds at both validation sites for the four GMFs. The RMSEs of the SAR-retrieved wind speeds are all below $1.0 \mathrm{~m} / \mathrm{s}: 0.74 \mathrm{~m} / \mathrm{s}$ (CMOD4), $0.86 \mathrm{~m} / \mathrm{s}$ (CMOD_IFR2_SDW), $0.64 \mathrm{~m} / \mathrm{s}$ (CMOD5) and $0.88 \mathrm{~m} / \mathrm{s}$ (CMOD5.N_SDW), and the biases are $-0.12 \mathrm{~m} / \mathrm{s}$ (CMOD4), $-0.15 \mathrm{~m} / \mathrm{s}$ (CMOD_IFR2_SDW), $0.20 \mathrm{~m} / \mathrm{s}$ (CMOD5) and $0.57 \mathrm{~m} / \mathrm{s}$ (CMOD5.N_SDW). All the negative biases shown in Figure 3 and 4 are obviously reduced in the case of only onshore wind.

Figure 5. Same as Figure 3, but for 22 onshore winds by IMP (daub circle) and WSM (square) at both Hiratsuka and Shirahama. The statistics are for 22 cases, and those for WSM (5 cases) are in parentheses.
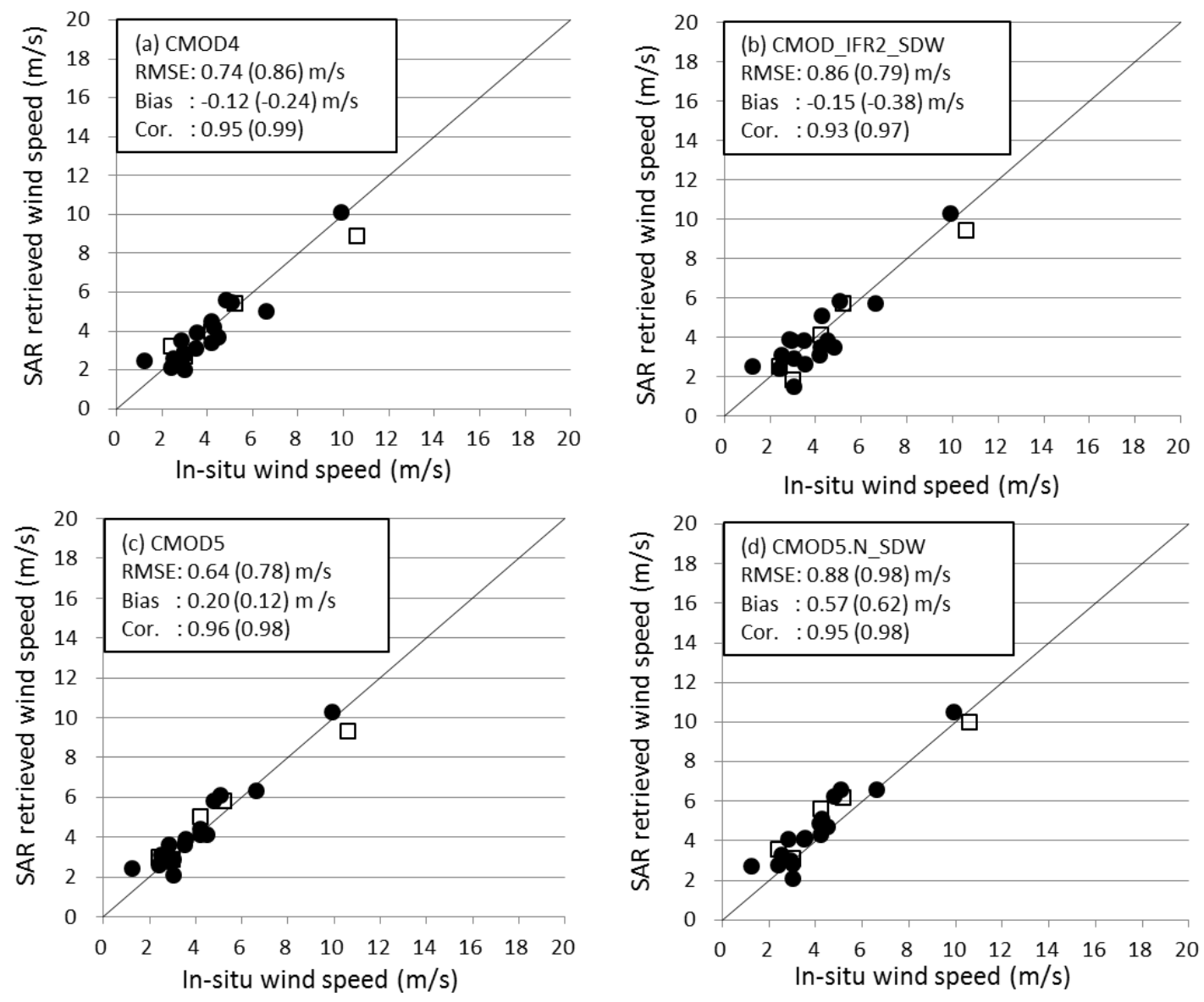

Meanwhile, Figure 6 shows the same scatter plots as Figure 5 but for 84 offshore winds. The RMSEs are $2.16 \mathrm{~m} / \mathrm{s}$ (CMOD4), $2.21 \mathrm{~m} / \mathrm{s}$ (CMOD_IFR2_SDW), $2.22 \mathrm{~m} / \mathrm{s}$ (CMOD5) and $2.03 \mathrm{~m} / \mathrm{s}$ 
(CMOD5.N_SDW), and the biases are $-1.38 \mathrm{~m} / \mathrm{s}$ (CMOD4), $-1.40 \mathrm{~m} / \mathrm{s}$ (CMOD_IFR2_SDW), $-0.99 \mathrm{~m} / \mathrm{s}$ (CMOD5) and $-0.81 \mathrm{~m} / \mathrm{s}$ (CMOD5.N_SDW). These statistic values are concluded in Table 2. All the RMSEs are greater than $2 \mathrm{~m} / \mathrm{s}$, and are obviously larger than those in Figures 3 and 4 . In addition, the negative bias is larger compared to those in Figure 3 and 4. These results demonstrate that the negative biases, shown in Figures 3 and 4, are mainly due to the short fetch effect. In addition, it is found that only the wind speeds retrieved from WSM images have smaller negative biases, compared to those from both mode images. This tendency cannot be found in the onshore wind case (Figure 5). These facts suggest that the wind speeds retrieved from the IMP image can be more easily affected by the short fetch.

Figure 6. Same as Figure 3, but for 84 offshore winds by IMP (daub circle) and WSM (square) at both Hiratsuka and Shirahama. The statistics are for 84 cases, and those for WSM (26 cases) are in parentheses.
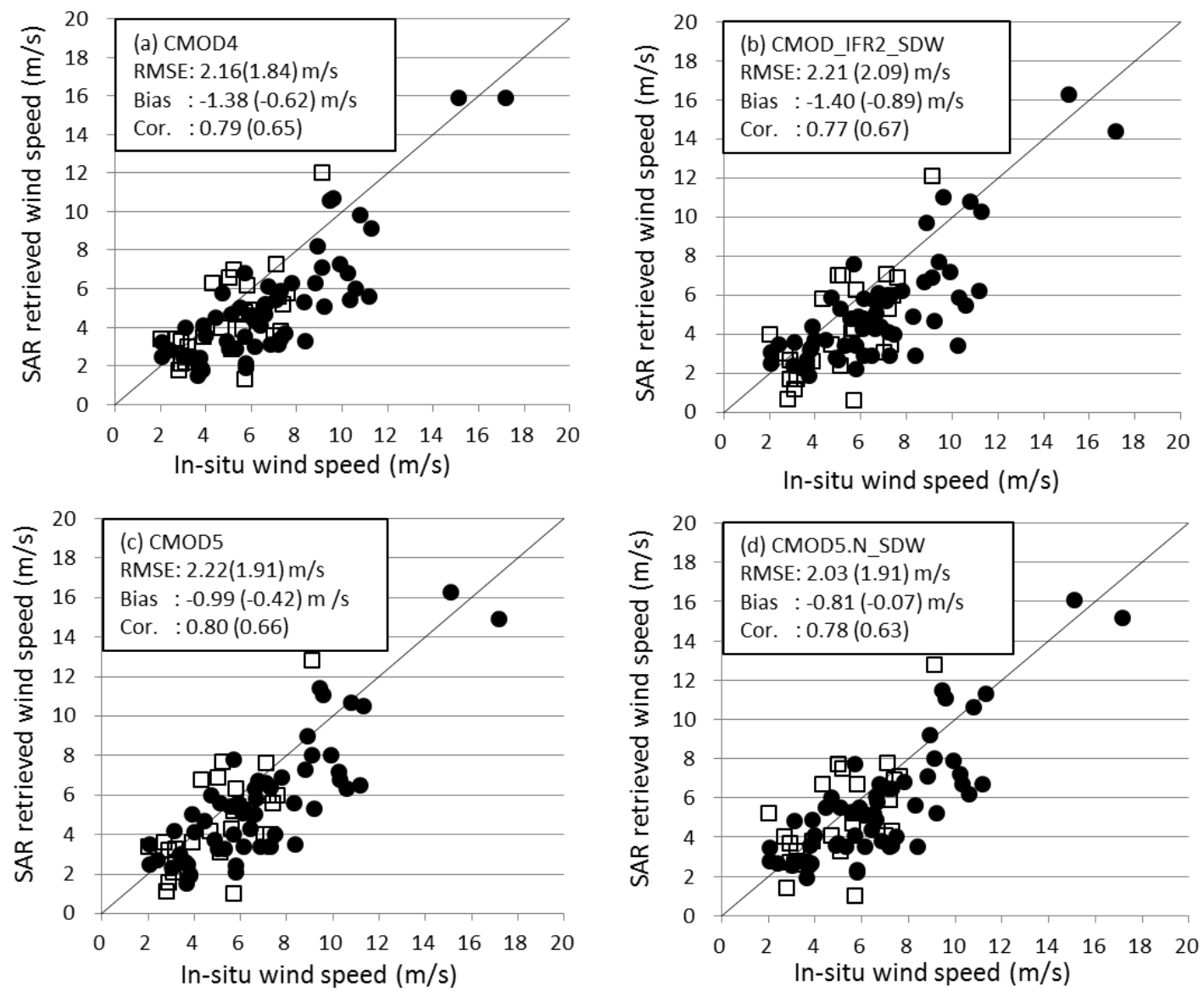

Table 2. RMSEs, biases and correlation coefficients of wind speeds retrieved by four GMFs at onshore and offshore winds.

\begin{tabular}{llrrrr}
\hline & & CMOD4 & CMOD_IFR2_SDW & CMOD5 & CMOD5.N_SDW \\
\hline \multirow{3}{*}{ Onshore } & RMSE (m/s) & 0.74 & 0.86 & 0.64 & 0.88 \\
& Bias (m/s) & -0.12 & -0.15 & 0.20 & 0.57 \\
& Correlation coef. & 0.95 & 0.93 & 0.96 & 0.95 \\
& RMSE (m/s) & 2.16 & 2.21 & 2.22 & 2.03 \\
Offshore & Bias (m/s) & -1.38 & -1.40 & -0.99 & -0.81 \\
& Correlation coef. & 0.79 & 0.77 & 0.80 & 0.78 \\
\hline
\end{tabular}




\subsection{Effectiveness of Atmospheric Stability Correction with CMOD5.N}

In this subsection, effectiveness of the atmospheric stability correction is examined. Figure 7 shows monthly differences between SDW and ENW for in situ measurements at Shirahama. Positive values indicate that SDW is larger than ENW. The differences between SDW and ENW range mostly between -0.9 and $-0.2 \mathrm{~m} / \mathrm{s}$ in the winter season (from October to March) when unstable conditions prevail, while the differences range from -0.5 to $1.2 \mathrm{~m} / \mathrm{s}$ in the summer season (from April to September) when neutral and stable conditions tend to occur. Roughly speaking, the differences range from -1 to $+1 \mathrm{~m} / \mathrm{s}$ throughout the year. In Figure 8 , monthly variation of the stability parameter $\mathrm{z} / \mathrm{L}$ is shown. The parameters do not appear unless the CMOD5.N-retrieved wind speed is $2 \mathrm{~m} / \mathrm{s}$ or higher because lower wind speeds give an extremely large value of the parameter. Figure 8 additionally shows that the stability parameter also indicates the seasonal variation of the atmospheric stability. In winter season, all values of $\mathrm{z} / \mathrm{L}$ range from -7 to 0 , while $\mathrm{z} / \mathrm{L}$ ranges between -4 and 1 in summer season. From Figures 7 and 8, it is found that the difference between SDW and ENW shows seasonal variation, which depends on the actual atmospheric stability. This suggest that the atmospheric stability can cause an error of -1 to $+1 \mathrm{~m} / \mathrm{s}$ in the SAR retrieved wind speed when using the GMFs that do not take into account the effect of atmospheric stability. Thus, the atmospheric stability correction is indispensable in the SAR wind speed retrieval in Japanese coastal water.

Figure 7. Monthly differences $(\mathrm{m} / \mathrm{s})$ between SDW and ENW for in situ measurements at Shirahama.

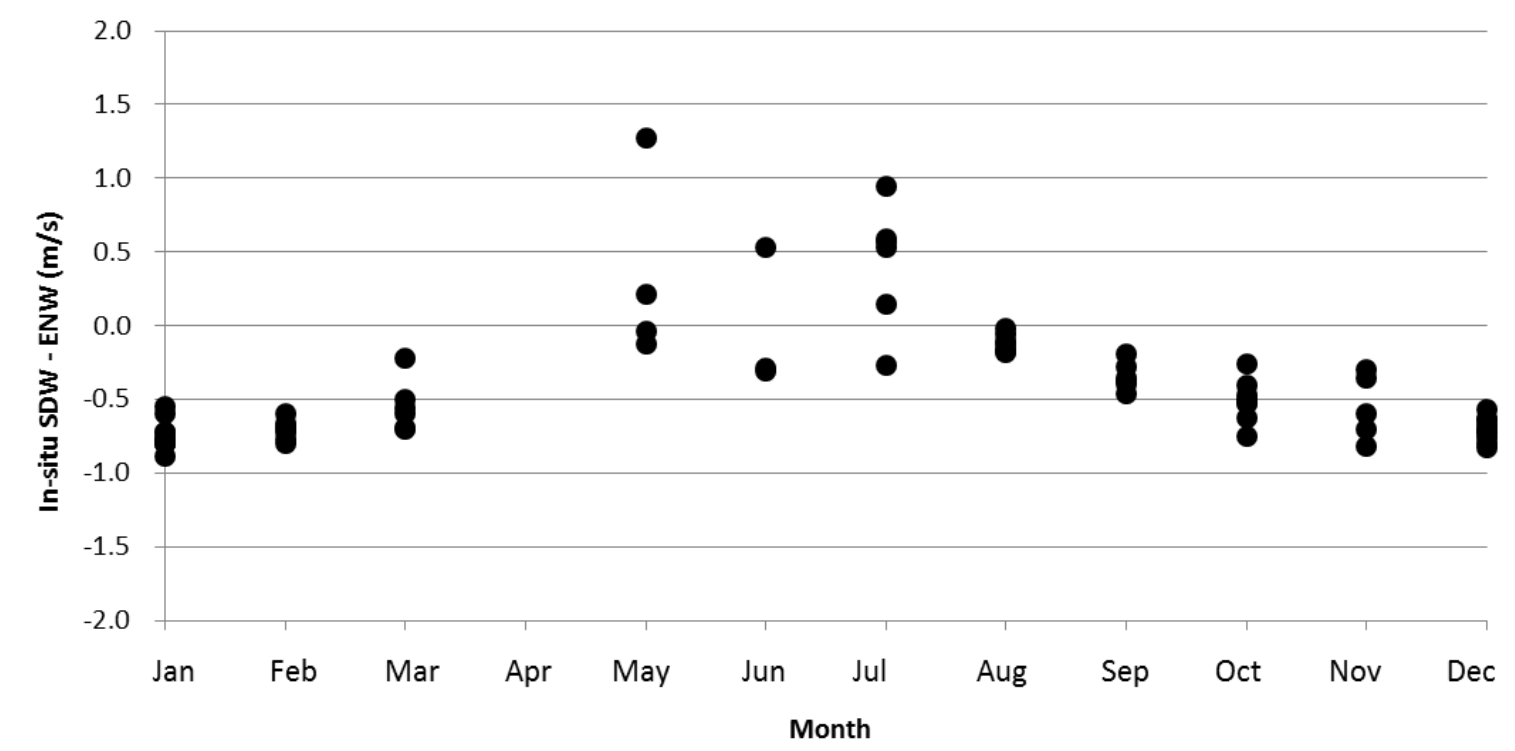

The relation between CMOD5, CMOD5.N_ENW and CMOD5.N_SDW is shown in Figure 9, based on the results in Section 3.1 and Figure 7. As shown in Figure 9, it is expected that the difference between CMOD5 and CMOD5.N_SDW decreases in the unstable condition, whereas it increases in the unstable condition. The small difference in the unstable condition is caused by the correction offset of about $0.7 \mathrm{~m} / \mathrm{s}$, which was enhanced when CMOD5. $\mathrm{N}$ had been developed from CMOD5 as shown in Figure 9.

In order to examine if CMOD5.N is effective for the atmospheric stability correction, the statistical values obtained from CMOD5.N_SDW and CMOD5 are shown in Table 3. In the neutral condition 
$(-1.0<\mathrm{z} / \mathrm{L} \leq 0.1)$, the RMSE with CMOD5.N_SDW $(1.72 \mathrm{~m} / \mathrm{s})$ is slightly larger than CMOD5 $(1.70 \mathrm{~m} / \mathrm{s})$. The differences of absolute biases are also few between CMOD5.N_SDW and CMOD5. Meanwhile, in unstable $(\mathrm{z} / \mathrm{L} \leq-1.0)$ and stable condition $(0.1<\mathrm{z} / \mathrm{L})$, CMOD5.N_SDW has a smaller RMSE than CMOD5. In particular, in the stable condition, the differences of RMSE and absolute biases between CMOD5.N_SDW and CMOD5.N are $0.15 \mathrm{~m} / \mathrm{s}$ and $0.68 \mathrm{~m} / \mathrm{s}$, respectively, and the difference between CMOD5.N_SDW and CMOD5 is remarkable. These results indicate that atmospheric stability should be taken into account in the SAR wind speed retrieval in the seas with non-neutral conditions, and CMOD5.N is effective for the atmospheric stability correction.

Figure 8. Monthly variation of $\mathrm{z} / \mathrm{L}$ at Shirahama. But only $2 \mathrm{~m} / \mathrm{s}$ or higher of the CMOD5.N-retrieved wind speed.

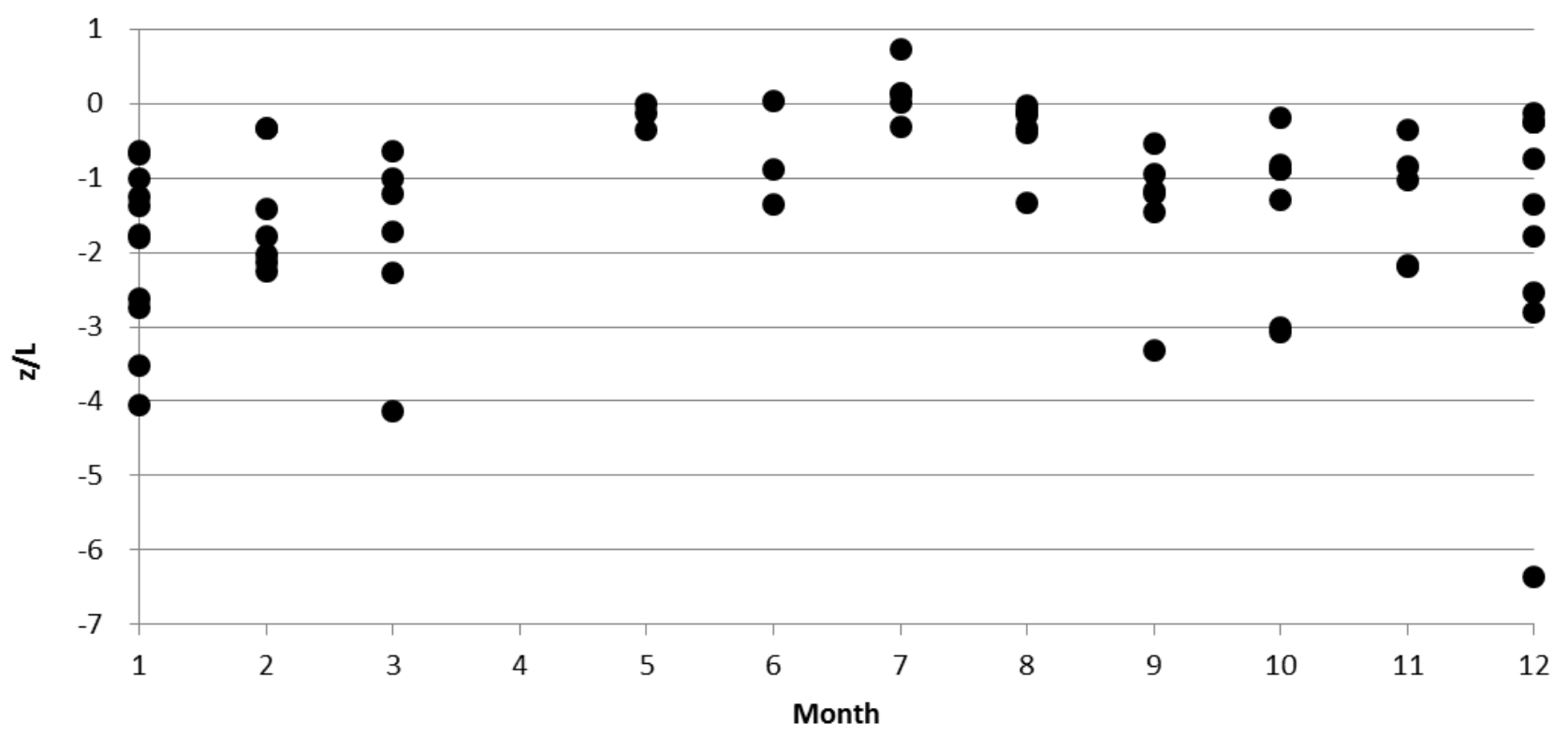

Figure 9. Relationship of retrieved wind speeds among CMOD5, CMOD5.N_ENW and CNOD5.N_SDW under stable and unstable atmospheric conditions.

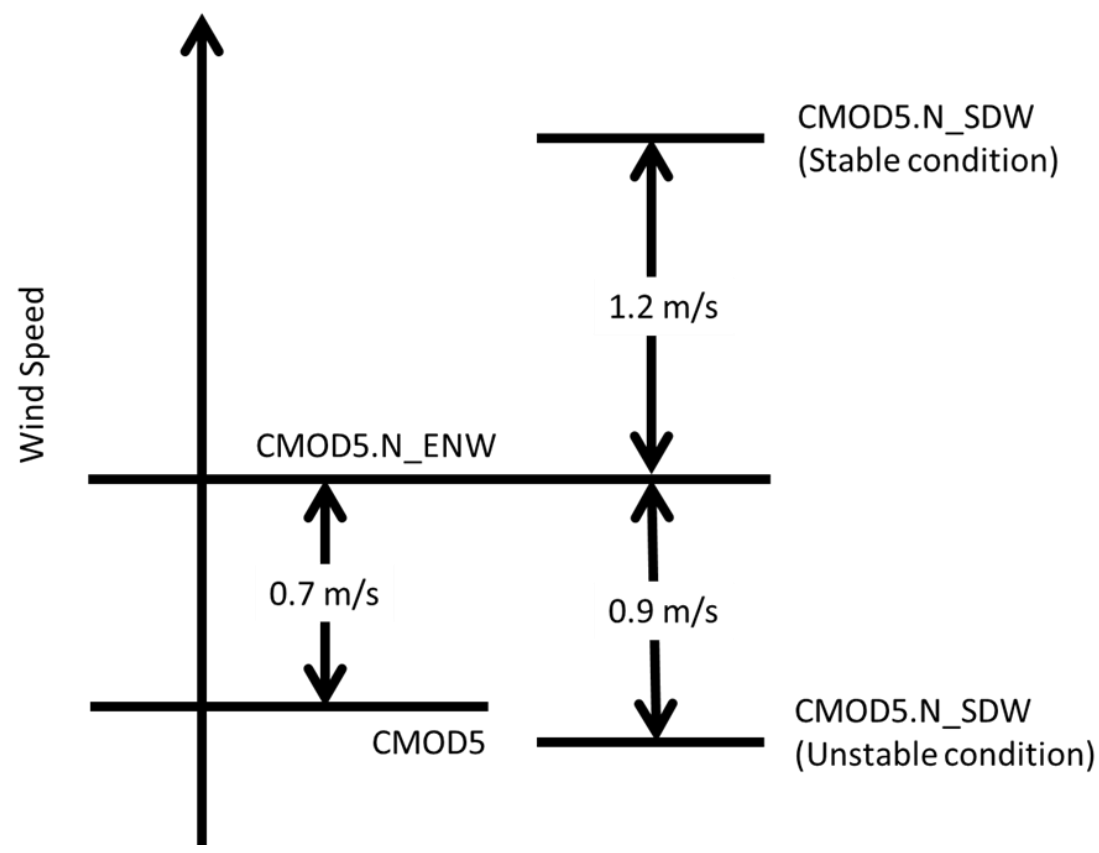


Table 3. Comparison of statistics between CMOD5.N_SDW and CMOD5.

\begin{tabular}{llrrr}
\hline \multirow{2}{*}{ Atmospheric Condition } & & $\begin{array}{l}\text { Unstable } \\
(\mathbf{z} / \mathbf{L} \leq-\mathbf{1 . 0})\end{array}$ & $\begin{array}{l}\text { Neutral } \\
(-\mathbf{1 . 0}<\mathbf{z} / \mathbf{L} \leq \mathbf{0 . 1})\end{array}$ & $\begin{array}{l}\text { Stable } \\
(\mathbf{0 . 1}<\mathbf{z} / \mathbf{L})\end{array}$ \\
\cline { 2 - 3 } Bias (m/s) & CMOD5.N_SDW & -0.97 & 0.16 & 0.36 \\
& CMOD5 & -1.01 & -0.11 & -1.04 \\
\multirow{2}{*}{ RMSE (m/s) } & CMOD5.N_SDW & 1.83 & 1.72 & 1.47 \\
& CMOD5 & 1.85 & 1.70 & 1.62 \\
\hline
\end{tabular}

\section{Conclusions}

In this paper, four C-band geophysical model functions (GMFs) for sea surface wind speed retrieval: CMOD4, CMOD_IFR2, CMOD5, and CMOD5.N, are compared using 106 SAR images at two validation sites, Hiratsuka and Shirahama, in Japanese coastal waters. The effect of the correction of atmospheric stability, which is taken into account in the latest GMF CMOD5.N, is also examined since atmospheric stability is variable in Japanese coastal waters. The main results of this study are summarized as follows.

1. Of all the GMFs, the stability-dependent wind speed (SDW) retrieved with CMOD5.N and corrected for atmospheric stability with the LKB code (CMOD5.N_SDW) has the smallest root mean square error (RMSE) and the smallest bias at both Hiratsuka and Shirahama. The RMSEs are $2.03 \mathrm{~m} / \mathrm{s}$ at Hiratsuka and $1.76 \mathrm{~m} / \mathrm{s}$ at Shirahama, and the biases are $-0.77 \mathrm{~m} / \mathrm{s}$ at Hiratsuka and $-0.42 \mathrm{~m} / \mathrm{s}$ at Shirahama.

2. All of the GMFs exhibit a negative bias in the retrieved wind speed at both validation sites. By contrasting winds blowing onshore and offshore, only offshore winds were found to have a large negative bias. This indicates that the negative bias is primarily caused by short fetches from a coastline.

3. Atmospheric stability can cause an error of about -1 to $+1 \mathrm{~m} / \mathrm{s}$ in the SAR retrieved wind speed at Shirahama when using the GMFs that do not take the effect of atmospheric stability into account. CMOD5.N can reduce this error especially in non-neutral conditions, indicating that the use of CMOD5.N is effective for the atmospheric stability correction.

In short, at the moment, CMOD5.N is thought to be the most promising GMF for SAR wind speed retrieval in Japanese coastal waters. However, it is also clear that there is still ample room for future improvement. For instance, it is necessary to examine a larger number of wind speed samples because the samples used in this study were mostly less than $12 \mathrm{~m} / \mathrm{s}$. Future work is also necessary for the investigation of the short fetch effect causing a large negative bias in winds blowing offshore.

\section{Acknowledgments}

ENVISAT Advanced SAR images were acquired from the European Space Agency under the co-operative research project "Offshore wind resource assessments using SAR and MM5 over Japanese coastal waters", C1P4068. The observation data at Shirahama were provided by former Yasunori Muto and Yasuyuki Baba at the Disaster Prevention Research Institute (DPRI), Kyoto University. The measurements at Hiratsuka were provided by Kanagawa Prefecture. Moreover, sea 
surface temperature data were obtained from the Center for Atmospheric and Oceanic Studies, Tohoku University. This study was supported by a Grant-in-Aid for Scientific Research (B) 22360379 and a Grant-in-Aid for Young Scientists (B) 24760679 from the Ministry of Education, Science, Sport and Culture, Japan. The authors are grateful to all of the above organizations and individuals. Comments from the editor and anonymous reviewers are also acknowledged.

\section{References}

1. APDRC. Available online: http://apdrc.soest.hawaii.edu/data/data.php (accessed on 10 October 2012).

2. Stoffelen, A.; Anderson, D. Scatterometer data interpretation: Estimation and validation of the transfer function CMOD-4. J. Geophys. Res. 1997, 102, 5767-5780.

3. Lehner, S.; Horstmann, J.; Koch, W.; Rosenthal, W. Mesoscale wind measurements using recalibrated ERS SAR images. J. Geophys. Res. 1998, 103, 7847-7856.

4. Horstmann, J.; Koch, W.; Lehner, S.; Tonboe, R. Ocean winds from RADARSAT-1 ScanSAR. Can. J. Remote Sens. 2002, 28, 524-533.

5. Hasager, C.B.; Dellwik, E.; Nielsen, M.; Furevik, B.R. Validation of ERS-2 SAR offshore wind-speed maps in the North Sea. Int. J. Remote Sen. 2004, 25, 3817-3841.

6. Stoffelen, A. Toward the true near-surface wind speed: Error modeling and calibration using triple collocation. J. Geophys. Res. 1998, 103, 7755-7766.

7. Quilfen, Y.; Chapron, B.; Elfouhaily, T.; Katsaros, K.; Tournadre, J. Observation of tropical cyclones by high-resolution scatterometry. J. Geophys. Res. 1998, 103, 7767-7786.

8. Hasager, C.B.; Badger, M.; Peña, A.; Larsén, X.G.; Bingöl, F. SAR-based wind resource statistics in the Baltic Sea. Remote Sens. 2011, 3, 117-144.

9. Hersbach, H.; Stoffelen, A.; Haan, S. An improved C-band scatterometer ocean geophysical model function: CMOD5. J. Geophys. Res. 2007, 112, 1-18.

10. Hersbach, H. Comparison of C-band scatterometer CMOD5.N equivalent neutral winds with ECMWF. J. Atm. Oceanic Tech. 2010, 27, 721-736.

11. Liu, W.T.; Tang, W. Equivalent Neutral Wind; 1996; pp. 96-178. Available online: http://airsea-www.jpl.nasa.gov/data (accessed on 10 October 2012).

12. Monin, A.S.; Obukhov, A.M. Basic laws of turbulent mixing in the surface layer of the atmosphere. Tr. Akad. Nauk SSSR Geophiz. Inst. 1954, 24, 164-187.

13. Cressman, G.P. An operational objective analysis system. Mon. Wea. Rev. 1959, 87, 67-374.

14. Takeyama, Y.; Ohsawa T., Kozai K.; Hasager C.B.; Badger M. Error Factors in SAR Wind Retrieval for Inshore Areas. In Proceedings of European Offshore Wind 2009 Conference \& Exhibition, Stockholm, Sweden, 14-16 September 2009; PO. 136, p. 10.

15. Shankaranarayanan, K.; Donelan, M.A. A probabilistic approach to scatterometer model function verification. J. Geophys. Res. 2001, 106, 19969-19990.

16. Vachon, P.W.; Dobson, F.W. Wind retrieval from radarsat sar images: Selection of a suitable C-band HH polarization wind retrieval model. Can. J. Rem. Sens. 2000, 26, 306-313.

17. ASCAT Wind Product User Manual; Version 1.12; 2012; p. 27. Available online: http://www.knmi.nl/scatterometer/publications/pdf/ASCAT_Product_Manual.pdf (accessed on 10 October 2012). 
18. Vachon, P.W.; Dobson, F.W. Validation of wind vector retrieval from ERS-1 SAR images over the ocean. Glob. Atmos. Ocean Syst. 1996, 5, 177-187.

19. Wackerman, C.; Rufenach, C.L.; Shuchman, R.A.; Johannessen, J.A.; Davidson, K.L. Wind vector retrieval using ERS-1 synthetic aperture radar imagery. IEEE Trans. Geosci. Remote Sens. 1996, 34, 1343-1352.

20. Takeyama, Y.; Ohsawa, T.; Kozai, K.; Hasager, C.B.; Badger, M. Effectiveness of weather research and forecasting wind direction for retrieving coastal sea surface wind from synthetic aperture radar. Wind Energy 2013, in press.

21. Mouche, A.A.; Hauser, D.; Daloze, J.; Gueri, C. Dual-Polarization measurements at C-Band over the ocean: Result from airborne radar observations and comparison with ENVISAT ASAR data. IEEE Trans. Geosci. Remote Sens. 2005, 43, 753-769.

22. Liu, W.T.; Katsaros, K.B.; Businger, J.A. Bulk parameterization of air-sea exchanges of heat and water vapor including the molecular constraints at the interface. J. Atmos. Sci. 1979, 36, 1722-1735.

23. The Weather Research and Forecasting Model. Available online: http://wrf-model.org/index.php (accessed on 10 October 2012).

24. Charnock, H. Wind stress on a water surface. Q. J. Roy. Meteor. Soc. 1955, 81, 639-640.

25. Abdalla, S.; Hersbach, H. The Technical Support for Global Validation of ERS Wind and Wave Products at ECMWF; Final Report for ESA Contract 15988/02/I-LG; 2004; p. 59. Available online: http://www.ecmwf.int/publications/library/ecpublications/_pdf/esa/ESA_abdalla_hersbach.pdf (accessed on 10 October 2012).

26. Portabella, M.; Stoffelen A. On scatterometer ocean stress. J. Atm. Oceanic Tech. 2009, 26, 368-382.

27. Shimada, T.; Kawamura, H.; Shimada, M. Evaluation of JERS-1 SAR images from a coastal wind retrieval point of view. IEEE Trans. Geosci. Remote Sens. 2004, 42, 491-500.

\section{Appendix}

Appendix 1. List of 33 ENVISAT Advanced SAR images with corresponding in situ measurements at Hiratsuka.

\begin{tabular}{|c|c|c|c|c|c|c|c|}
\hline \multirow[b]{2}{*}{$\begin{array}{c}\text { Date } \\
\text { (year/month/day) }\end{array}$} & \multirow{2}{*}{$\begin{array}{l}\text { SAR } \\
\text { Time } \\
\text { (hr:min:sec) }\end{array}$} & \multirow[b]{2}{*}{ Polarization } & \multirow[b]{2}{*}{$\begin{array}{c}\text { Observation } \\
\text { Mode }\end{array}$} & \multicolumn{2}{|c|}{ In situ } & \multicolumn{2}{|c|}{ WRF } \\
\hline & & & & $\begin{array}{c}\text { Wind } \\
\text { Direction } \\
\left({ }^{\circ} \mathbf{C}\right)\end{array}$ & $\begin{array}{l}\text { Wind Speed } \\
\left(\mathbf{m} \cdot \mathrm{s}^{-1}\right) \\
\text { at } 10 \mathrm{~m}\end{array}$ & $\begin{array}{l}\text { Sea Temp. } \\
\quad\left({ }^{\circ} \mathrm{C}\right)\end{array}$ & $\begin{array}{c}\text { Air Temp. } \\
\quad\left({ }^{\circ} \mathbf{C}\right)\end{array}$ \\
\hline $2003 / 02 / 01$ & $00: 54: 51$ & VV & IMP & 3 & 6.1 & 17.8 & 8.6 \\
\hline $2003 / 02 / 17$ & $00: 51: 57$ & VV & IMP & 350 & 3.7 & 18.1 & 11.6 \\
\hline $2003 / 06 / 21$ & $00: 54: 56$ & VV & IMP & 213 & 3.8 & 23.8 & 25.3 \\
\hline $2003 / 07 / 26$ & 00:55:00 & VV & IMP & 5 & 5.8 & 24.3 & 25.5 \\
\hline $2003 / 08 / 30$ & 00:55:04 & VV & IMP & 19 & 3.6 & 26.5 & 28.0 \\
\hline $2003 / 10 / 04$ & $00: 55: 00$ & VV & IMP & 38 & 3.4 & 26.0 & 21.0 \\
\hline $2003 / 10 / 20$ & $00: 52: 06$ & VV & IMP & 1 & 8.4 & 24.2 & 18.5 \\
\hline 2003/11/08 & $00: 54: 56$ & VV & IMP & 117 & 3.0 & 24.4 & 20.9 \\
\hline $2003 / 12 / 25$ & $12: 31: 35$ & VV & IMP & 233 & 17.2 & 20.2 & 15.7 \\
\hline
\end{tabular}


Appendix 1. Cont.

\begin{tabular}{|c|c|c|c|c|c|c|c|}
\hline \multirow[b]{2}{*}{$\begin{array}{c}\text { Date } \\
\text { (year/month/day) }\end{array}$} & \multicolumn{2}{|l|}{ SAR } & \multirow[b]{2}{*}{$\begin{array}{c}\text { Observation } \\
\text { Mode }\end{array}$} & \multicolumn{2}{|c|}{ In situ } & \multicolumn{2}{|c|}{ WRF } \\
\hline & $\begin{array}{c}\text { Time } \\
\text { (hr:min:sec) }\end{array}$ & Polarization & & $\begin{array}{c}\text { Wind } \\
\text { Direction } \\
\left({ }^{\circ} \mathbf{C}\right) \\
\end{array}$ & $\begin{array}{c}\text { Wind Speed } \\
\qquad\left(\mathbf{m} \cdot \mathrm{s}^{-1}\right) \\
\text { at } 10 \mathrm{~m} \\
\end{array}$ & $\begin{array}{c}\text { Sea Temp. } \\
\left({ }^{\circ} \mathbf{C}\right)\end{array}$ & $\begin{array}{c}\text { Air Temp. } \\
\left({ }^{\circ} \mathrm{C}\right)\end{array}$ \\
\hline $2003 / 12 / 29$ & 00:52:09 & $\mathrm{VV}$ & IMP & 259 & 9.4 & 20.1 & 13.4 \\
\hline $2005 / 10 / 05$ & $00: 49: 22$ & $\mathrm{HH}$ & IMP & 40 & 3.0 & 22.6 & 22.0 \\
\hline $2005 / 11 / 25$ & 00:46:29 & $\mathrm{HH}$ & IMP & 24 & 4.7 & 22.9 & 14.8 \\
\hline $2005 / 12 / 30$ & 00:46:22 & $\mathrm{HH}$ & IMP & 18 & 2.4 & 16.9 & 7.2 \\
\hline $2006 / 03 / 10$ & 00:46:20 & $\mathrm{HH}$ & IMP & 357 & 10.2 & 17.1 & 10.2 \\
\hline $2006 / 05 / 19$ & 00:46:26 & $\mathrm{HH}$ & IMP & 17 & 4.4 & 20.5 & 21.5 \\
\hline $2006 / 06 / 23$ & 00:46:31 & $\mathrm{HH}$ & IMP & 298 & 2.0 & 22.6 & 22.4 \\
\hline $2006 / 07 / 28$ & $00: 46: 32$ & $\mathrm{HH}$ & IMP & 168 & 4.3 & 24.4 & 25.4 \\
\hline $2007 / 01 / 22$ & 00:52:02 & VV & IMP & 352 & 7.5 & 18.7 & 9.7 \\
\hline $2007 / 05 / 04$ & $00: 46: 26$ & $\mathrm{HH}$ & IMP & 121 & 3.6 & 21.6 & 20.2 \\
\hline $2007 / 05 / 07$ & 00:52:06 & $\mathrm{HH}$ & IMP & 174 & 3.0 & 21.1 & 19.8 \\
\hline $2007 / 06 / 08$ & $00: 46: 28$ & VV & IMP & 146 & 4.2 & 21.7 & 21.2 \\
\hline $2007 / 08 / 17$ & 00:46:28 & $\mathrm{HH}$ & IMP & 146 & 2.8 & 29.4 & 30.7 \\
\hline $2007 / 09 / 21$ & $00: 46: 23$ & VV & IMP & 183 & 1.2 & 25.9 & 25.7 \\
\hline $2007 / 11 / 17$ & 00:54:53 & $\mathrm{VV}$ & IMP & 3 & 5.8 & 22.8 & 13.7 \\
\hline $2007 / 11 / 30$ & 00:46:19 & $\mathrm{HH}$ & IMP & 353 & 6.4 & 20.2 & 13.3 \\
\hline $2007 / 12 / 03$ & 00:51:59 & $\mathrm{HH}$ & IMP & 212 & 7.2 & 19.6 & 15.3 \\
\hline $2008 / 04 / 21$ & 00:52:00 & VV & IMP & 8 & 6.9 & 19.3 & 19.7 \\
\hline $2008 / 06 / 27$ & $00: 46: 22$ & $\mathrm{HH}$ & IMP & 83 & 3.1 & 21.0 & 22.2 \\
\hline 2008/08/01 & 00:46:22 & $\mathrm{HH}$ & IMP & 165 & 2.9 & 22.2 & 20.9 \\
\hline 2008/10/13 & 00:52:00 & VV & IMP & 113 & 4.8 & 27.6 & 27.1 \\
\hline 2008/11/14 & 00:46:23 & $\mathrm{HH}$ & IMP & 23 & 6.1 & 24.6 & 21.5 \\
\hline $2008 / 11 / 17$ & 00:51:57 & VV & IMP & 354 & 6.5 & 21.4 & 17.5 \\
\hline $2008 / 12 / 22$ & 00:51:59 & VV & IMP & 91 & 2.0 & 22.6 & 17.9 \\
\hline
\end{tabular}

Appendix 2. Same as Appendix 1, but for 73 images and in situ measurements at Shirahama.

\begin{tabular}{cccccccc}
\hline $\begin{array}{c}\text { Date } \\
(\text { year/month/day) }\end{array}$ & $\begin{array}{c}\text { SAR } \\
\text { Time } \\
(\text { hr:min:sec) }\end{array}$ & Polarization & $\begin{array}{c}\text { Observation } \\
\text { Mode }\end{array}$ & $\begin{array}{c}\text { Wind } \\
\text { Direction }\left({ }^{\circ} \mathbf{C}\right)\end{array}$ & $\begin{array}{c}\text { In situ } \\
\text { Wind Speed }(\mathbf{m} / \mathbf{s}) \\
\text { at 10 m }\end{array}$ & $\begin{array}{c}\text { Sea Temp. } \\
\left({ }^{\circ} \mathbf{C}\right)\end{array}$ & $\begin{array}{c}\text { Air Temp. } \\
\left({ }^{\circ} \mathbf{C}\right)\end{array}$ \\
\hline 2003/05/07 & $01: 09: 47$ & VV & IMP & 114 & 3.6 & 22.1 & 22.4 \\
$2003 / 07 / 16$ & $01: 09: 53$ & VV & IMP & 296 & 6.6 & 25.2 & 23.6 \\
$2003 / 09 / 24$ & $01: 09: 56$ & VV & IMP & 59 & 11.2 & 26.2 & 22.4 \\
$2003 / 10 / 29$ & $01: 09: 50$ & VV & IMP & 347 & 10.3 & 24.2 & 16.8 \\
$2003 / 12 / 19$ & $01: 07: 03$ & VV & IMP & 347 & 15.1 & 20.2 & 8.3 \\
$2004 / 01 / 23$ & $01: 07: 00$ & VV & IMP & 322 & 7.8 & 16.9 & 4.0 \\
$2004 / 02 / 11$ & $01: 09: 51$ & VV & IMP & 320 & 3.9 & 17.0 & 8.3 \\
$2004 / 02 / 27$ & $01: 07: 00$ & VV & IMP & 308 & 9.9 & 16.4 & 6.9 \\
$2004 / 05 / 07$ & $01: 07: 00$ & VV & IMP & 268 & 4.5 & 20.5 & 20.7 \\
2004/06/30 & $01: 09: 55$ & VV & IMP & 64 & 5.3 & 25.6 & 24.7 \\
\hline
\end{tabular}


Appendix 2. Cont.

\begin{tabular}{|c|c|c|c|c|c|c|c|}
\hline \multirow[b]{2}{*}{$\begin{array}{c}\text { Date } \\
\text { (year/month/day) } \\
\end{array}$} & \multicolumn{2}{|l|}{ SAR } & \multirow[b]{2}{*}{$\begin{array}{c}\text { Observation } \\
\text { Mode }\end{array}$} & \multicolumn{4}{|c|}{ In situ } \\
\hline & $\begin{array}{c}\text { Time } \\
\text { (hr:min:sec) }\end{array}$ & Polarization & & $\begin{array}{c}\text { Wind } \\
\text { Direction }\left({ }^{\circ} \mathbf{C}\right)\end{array}$ & $\begin{array}{c}\text { Wind Speed }(\mathrm{m} / \mathrm{s}) \\
\text { at } 10 \mathrm{~m}\end{array}$ & $\begin{array}{c}\text { Sea Temp. } \\
\left({ }^{\circ} \mathbf{C}\right)\end{array}$ & $\begin{array}{c}\text { Air Temp. } \\
\left({ }^{\circ} \mathbf{C}\right)\end{array}$ \\
\hline $2004 / 07 / 31$ & $12: 48: 26$ & VV & IMP & 115 & 11.3 & 27.0 & 28.6 \\
\hline $2004 / 08 / 20$ & 01:07:04 & $\mathrm{VV}$ & IMP & 259 & 5.1 & 27.7 & 27.6 \\
\hline 2004/09/08 & 01:09:55 & $\mathrm{VV}$ & IMP & 286 & 2.5 & 27.2 & 26.1 \\
\hline $2004 / 10 / 13$ & 01:09:56 & $\mathrm{VV}$ & IMP & 20 & 8.9 & 24.8 & 21.8 \\
\hline $2004 / 10 / 29$ & 01:07:06 & $\mathrm{VV}$ & IMP & 93 & 5.7 & 22.8 & 19.6 \\
\hline $2005 / 01 / 07$ & 01:06:58 & $\mathrm{VV}$ & IMP & 10 & 7.3 & 16.2 & 10.7 \\
\hline $2005 / 02 / 11$ & 01:07:01 & $\mathrm{VV}$ & IMP & 331 & 6.1 & 15.8 & 5.8 \\
\hline $2005 / 05 / 11$ & 01:09:59 & VV & IMP & 247 & 3.5 & 17.6 & 18.2 \\
\hline $2005 / 05 / 27$ & 01:07:07 & VV & IMP & 176 & 3.8 & 19.0 & 23.1 \\
\hline $2005 / 10 / 14$ & 01:07:05 & $\mathrm{VV}$ & IMP & 96 & 5.0 & 25.7 & 24.7 \\
\hline $2005 / 11 / 18$ & 01:07:03 & $\mathrm{VV}$ & IMP & 6 & 6.8 & 22.0 & 13.2 \\
\hline $2005 / 12 / 23$ & 01:06:57 & $\mathrm{VV}$ & IMP & 326 & 9.6 & 15.4 & 6.8 \\
\hline $2006 / 01 / 11$ & 01:09:42 & $\mathrm{VV}$ & IMP & 358 & 5.9 & 18.2 & 8.5 \\
\hline $2006 / 03 / 03$ & 01:06:54 & VV & IMP & 317 & 9.1 & 15.1 & 5.9 \\
\hline $2007 / 08 / 29$ & 01:09:47 & $\mathrm{VV}$ & IMP & 244 & 2.4 & 29.1 & 28.5 \\
\hline $2007 / 11 / 07$ & 01:09:43 & $\mathrm{VV}$ & IMP & 16 & 4.0 & 23.9 & 18.0 \\
\hline $2007 / 11 / 23$ & 01:06:48 & $\mathrm{VV}$ & IMP & 352 & 9.9 & 21.8 & 10.3 \\
\hline $2007 / 12 / 08$ & $12: 48: 10$ & vV & IMP & 176 & 5.7 & 20.5 & 11.1 \\
\hline $2007 / 12 / 09$ & 01:03:59 & vV & IMP & 340 & 8.3 & 20.4 & 10.4 \\
\hline $2008 / 01 / 12$ & $12: 48: 12$ & vV & IMP & 348 & 8.8 & 20.3 & 9.8 \\
\hline $2008 / 01 / 13$ & 01:04:01 & $\mathrm{VV}$ & IMP & 347 & 9.2 & 20.0 & 6.5 \\
\hline 2008/01/16 & 01:09:43 & VV & IMP & 349 & 7.1 & 18.4 & 7.9 \\
\hline $2008 / 01 / 31$ & 12:51:01 & $\mathrm{VV}$ & IMP & 7 & 6.6 & 17.6 & 6.0 \\
\hline 2008/02/01 & 01:06:50 & $\mathrm{VV}$ & IMP & 355 & 5.5 & 17.5 & 5.7 \\
\hline $2008 / 02 / 16$ & 12:48:09 & $\mathrm{VV}$ & IMP & 323 & 10.8 & 15.3 & 4.7 \\
\hline $2008 / 02 / 17$ & 01:03:59 & $\mathrm{VV}$ & IMP & 342 & 10.6 & 15.1 & 1.7 \\
\hline $2008 / 02 / 20$ & 01:09:42 & $\mathrm{VV}$ & IMP & 345 & 6.6 & 16.8 & 6.9 \\
\hline 2008/03/06 & 12:51:02 & $\mathrm{VV}$ & IMP & 72 & 4.9 & 16.7 & 7.0 \\
\hline $2008 / 03 / 07$ & 01:06:51 & $\mathrm{VV}$ & IMP & 337 & 6.7 & 16.6 & 9.0 \\
\hline $2008 / 03 / 22$ & $12: 48: 13$ & $\mathrm{VV}$ & IMP & 244 & 4.2 & 17.5 & 12.3 \\
\hline $2008 / 03 / 23$ & 01:04:02 & VV & IMP & 159 & 7.3 & 18.3 & 13.5 \\
\hline $2008 / 03 / 26$ & 01:09:43 & $\mathrm{VV}$ & IMP & 354 & 5.1 & 18.2 & 12.9 \\
\hline $2010 / 06 / 25$ & 01:01:06 & VV & WSM & 84 & 3.1 & 24.1 & 23.4 \\
\hline $2010 / 07 / 11$ & 01:01:03 & $\mathrm{VV}$ & WSM & 168 & 7.4 & 24.0 & 26.1 \\
\hline $2010 / 07 / 27$ & 01:01:00 & $\mathrm{VV}$ & WSM & 184 & 2 & 27.0 & 30.7 \\
\hline $2010 / 07 / 30$ & 01:01:06 & VV & WSM & 205 & 2.9 & 26.4 & 27.8 \\
\hline $2010 / 08 / 12$ & 00:00:57 & $\mathrm{VV}$ & WSM & 218 & 10.6 & 27.8 & 28.2 \\
\hline $2010 / 08 / 15$ & 01:01:03 & VV & WSM & 211 & 5.2 & 28.4 & 28.8 \\
\hline $2010 / 08 / 18$ & 01:01:09 & VV & WSM & 286 & 4.2 & 28.2 & 28.7 \\
\hline $2010 / 08 / 31$ & 01:01:00 & $\mathrm{VV}$ & WSM & 223 & 2.4 & 29.0 & 29.3 \\
\hline 2010/09/03 & 01:01:06 & $\mathrm{VV}$ & WSM & 267 & 3 & 29.6 & 28.3 \\
\hline
\end{tabular}


Appendix 2. Cont.

\begin{tabular}{|c|c|c|c|c|c|c|c|}
\hline \multirow[b]{2}{*}{$\begin{array}{c}\text { Date } \\
\text { (year/month/day) }\end{array}$} & \multicolumn{2}{|l|}{ SAR } & \multirow[b]{2}{*}{$\begin{array}{c}\text { Observation } \\
\text { Mode }\end{array}$} & \multicolumn{4}{|c|}{ In situ } \\
\hline & $\begin{array}{c}\text { Time } \\
\text { (hr:min:sec) }\end{array}$ & Polarization & & $\begin{array}{c}\text { Wind } \\
\text { Direction }\left({ }^{\circ} \mathbf{C}\right)\end{array}$ & $\begin{array}{c}\text { Wind Speed }(\mathrm{m} / \mathrm{s}) \\
\text { at } 10 \mathrm{~m}\end{array}$ & $\begin{array}{c}\text { Sea Temp. } \\
\left({ }^{\circ} \mathbf{C}\right)\end{array}$ & $\begin{array}{c}\text { Air Temp } \\
\left({ }^{\circ} \mathbf{C}\right) \\
\end{array}$ \\
\hline $2011 / 10 / 30$ & 01:01:07 & $\mathrm{VV}$ & WSM & 30 & 2.8 & 24.2 & 19.8 \\
\hline $2011 / 12 / 07$ & 01:01:14 & $\mathrm{VV}$ & WSM & 359 & 5.7 & 21.7 & 14.5 \\
\hline $2011 / 12 / 10$ & 01:01:04 & $\mathrm{VV}$ & WSM & 33 & 4.3 & 21.5 & 9.5 \\
\hline $2011 / 12 / 18$ & 01:01:11 & VV & WSM & 3 & 9.1 & 21.2 & 8.4 \\
\hline $2010 / 06 / 27$ & 12:12:56 & $\mathrm{VV}$ & WSM & 187 & 5 & 24.0 & 25.4 \\
\hline $2010 / 07 / 13$ & $12: 12: 53$ & VV & WSM & 164 & 7.6 & 23.9 & 26.1 \\
\hline $2010 / 08 / 14$ & $12: 12: 47$ & VV & WSM & 176 & 5.6 & 28.2 & 28.0 \\
\hline $2010 / 09 / 05$ & 12:12:56 & VV & WSM & 104 & 2.7 & 29.9 & 27.8 \\
\hline $2010 / 09 / 18$ & 12:12:47 & $\mathrm{VV}$ & WSM & 95 & 3.2 & 27.7 & 24.0 \\
\hline $2010 / 09 / 21$ & $12: 12: 53$ & VV & WSM & 103 & 2.9 & 27.7 & 26.4 \\
\hline $2011 / 10 / 18$ & $12: 12: 58$ & VV & WSM & 108 & 3.9 & 25.4 & 18.5 \\
\hline $2011 / 10 / 26$ & 13:13:04 & VV & WSM & 29 & 5.2 & 24.5 & 14.6 \\
\hline $2011 / 10 / 29$ & $12: 12: 54$ & VV & WSM & 119 & 5.1 & 24.2 & 19.1 \\
\hline 2011/11/06 & 13:13:01 & $\mathrm{VV}$ & WSM & 355 & 5.8 & 23.8 & 21.5 \\
\hline $2011 / 11 / 25$ & 13:13:04 & VV & WSM & 18 & 5.9 & 21.8 & 11.0 \\
\hline 2011/12/06 & 13:13:01 & VV & WSM & 23 & 4.7 & 21.8 & 13.6 \\
\hline $2011 / 12 / 17$ & $12: 12: 58$ & $\mathrm{VV}$ & WSM & 26 & 5.7 & 20.3 & 7.9 \\
\hline $2011 / 12 / 28$ & $12: 12: 55$ & $\mathrm{VV}$ & WSM & 71 & 3.2 & 18.9 & 6.5 \\
\hline 2012/01/06 & 01:01:15 & VV & WSM & 14 & 7.3 & 18.0 & 6.6 \\
\hline 2012/01/09 & 01:01:05 & VV & WSM & 24 & 7.1 & 17.9 & 9.5 \\
\hline $2012 / 01 / 05$ & 13:13:01 & $\mathrm{VV}$ & WSM & 27 & 7.2 & 18.3 & 6.3 \\
\hline $2012 / 01 / 16$ & $12: 12: 58$ & $\mathrm{VV}$ & WSM & 46 & 7 & 18.3 & 6.4 \\
\hline
\end{tabular}

Appendix 3. The model configuration used in the WRF simulation is shown.

\section{Initial data}

Vertical resolution

Nesting option

Domain

Horizontal

Grid points

Time step

Surface layer

Planetary Boundary

Layer

Short wave radiation

Physics

option
Long wave radiation

Cloud microphysics

Cumulus

parameterization

Land surface
MANAL

NGSST $\left(0.05^{\circ} \times 0.05^{\circ}\right.$, daily $)$

28 levels

(surface to $10 \mathrm{hPa}$ )

two-way nesting

Domain 1

Domain 2

Domain 3

$4.5 \mathrm{~km}$

$1.5 \mathrm{~km}$

$0.5 \mathrm{~km}$

$100 \times 100$

$100 \times 100$

$100 \times 100$

$27 \mathrm{sec}$

$9 \mathrm{sec}$

$3 \mathrm{sec}$

Monin-Obukhov (Janjic Eta)

Mellor-Yamada-Janjic

(Eta) TKE

Dudhia

RRTM

WSM3

Kain-Fritsch (new Eta) none none

Five-layer soil 
Appendix 3. Cont.

\begin{tabular}{llll}
\hline \multirow{2}{*}{ 4dda option } & $\begin{array}{l}\text { Enable } \\
\text { including PBL }\end{array}$ & $\begin{array}{l}\text { Enable } \\
\text { excluding PBL }\end{array}$ & $\begin{array}{l}\text { Enable } \\
\text { excluding BL }\end{array}$ \\
\hline
\end{tabular}

MANAL: Japan Meteorological Agency Meso-Analysis; NGSST: New Generation Sea Surface Temperature;

PBL: Planetary Boundary Layer.

(C) 2013 by the authors; licensee MDPI, Basel, Switzerland. This article is an open access article distributed under the terms and conditions of the Creative Commons Attribution license (http://creativecommons.org/licenses/by/3.0/). 